\title{
The Florida Melanoma Trial I: A Prospective Multicenter Phase I/II Trial of Postoperative Hypofractionated Adjuvant Radiotherapy with Concurrent Interferon-Alfa-2b in the Treatment of Advanced Stage III Melanoma with Long-Term Toxicity Follow-Up
}

\author{
Steven E. Finkelstein, ${ }^{1,2}$ Andy Trotti, ${ }^{1}$ Nikhil Rao, ${ }^{1}$ \\ Douglas Reintgen, ${ }^{3}$ Wayne Cruse, ${ }^{3,4}$ Lynn Feun, ${ }^{5}$ Vernon Sondak, ${ }^{4}$ Daohai Yu, ${ }^{6}$ \\ Weiwei Zhu, ${ }^{6}$ Clement Gwede, ${ }^{7}$ and Ronald DeConti ${ }^{4}$ \\ ${ }^{1}$ Department of Radiation Oncology, Moffitt Cancer Center, Tampa, FL 33612, USA \\ ${ }^{2} 21$ st Century Oncology Translational Research Consortium, Scottsdale, AZ 85251, USA \\ ${ }^{3}$ Department of Surgery, University of South Florida, Tampa, FL 33612, USA \\ ${ }^{4}$ Department of Cutaneous Oncology, Moffitt Cancer Center, Tampa, FL 33612, USA \\ ${ }^{5}$ Sylvester Comprehensive Cancer Center, University of Miami, Miami, FL 33146, USA \\ ${ }^{6}$ Department of Biostatistics, Moffitt Cancer Center, Tampa, FL 33612, USA \\ ${ }^{7}$ Health Outcomes \& Behavior Program, Moffitt Cancer Center, Tampa, FL 33612, USA \\ Correspondence should be addressed to Steven E. Finkelstein, sfinkels@rtsx.com \\ and Ronald DeConti, ronald.deconti@moffitt.org
}

Received 8 September 2011; Accepted 16 October 2011

Academic Editors: A. Bensussan and D. Saverino

Copyright ( $) 2012$ Steven E. Finkelstein et al. This is an open access article distributed under the Creative Commons Attribution License, which permits unrestricted use, distribution, and reproduction in any medium, provided the original work is properly cited.

Radiotherapy (RT) and interferon-alfa-2b (IFN $\alpha-2 \mathrm{~b}$ ) have individually been used for adjuvant therapy stage III melanoma with high-risk pathologic features. We hypothesized that concurrent adjuvant RT and IFN $\alpha$ - $2 \mathrm{~b}$ may decrease the risk of regional recurrence following surgery with acceptable toxicity. A prospective multicenter phase I/II study was conducted to evaluate hypofractionated RT with concurrent IFN. Induction IFN $\alpha-2 b, 20 \mathrm{MU} / \mathrm{m}^{2} / \mathrm{d}$, was administered IV $\times 5$ consecutive days every week for 4 weeks. Next, RT 30 Gy in 5 fractions was given with concurrent IFN $\alpha-2 b, 10 \mathrm{MU} / \mathrm{m}^{2}$ SQ 3 times per week on days alternating with RT. Subsequent maintenance therapy consisted of adjuvant IFN $\alpha-2 b, 10 \mathrm{MU} / \mathrm{m}^{2}$ SQ 3 times per week to a total of 1 year. To fully evaluate patterns of failure, long-term follow-up was conducted for up to 10 years. A total of 29 consenting patients were enrolled between August 1997 and March 2000. The maximum (worst) grade of acute nonhematologic toxicity during concurrent RT/IFN $\alpha$-2b (and up to 2 weeks post RT) was grade 3 skin toxicity noted in 2 patients (9\%). Late effects were limited. Probability of regional control was 78\% (95\% CI: 55\%-90\%) at 12 months. The median follow-up (range) was 80 (51-106) months among ten survivors (43\%). The median overall survival was 34.5 months while the median failure-free survival was 19.9 months. Postoperative concurrent hypofractionated RT with IFN $\alpha$-2b for advanced stage III melanoma appears to be associated with acceptable toxicity and may provide reasonable in-field control in patients at high risk of regional failure.

\section{Introduction}

Results with early stage melanoma have been generally good with high rates of local control and survival [1]. However, some patients with advanced primaries and/or nodal disease have not fared as well with surgery alone [2]. Despite wide excisions of the primary and aggressive dissections of the affected nodal basins, some patients with high-risk disease suffer unacceptable rates of local, regional, and distant failure [3]. Data from multiple institutions suggest that 
TABLe 1: Baseline characteristics $(n=23)$.

\begin{tabular}{|c|c|}
\hline & $n(\%)$ \\
\hline \multicolumn{2}{|l|}{ Sex } \\
\hline M & $13(56.5)$ \\
\hline $\mathrm{F}$ & $10(43.5)$ \\
\hline \multicolumn{2}{|l|}{ Race } \\
\hline White & $22(95.7)$ \\
\hline Hispanic & $1(4.3)$ \\
\hline \multicolumn{2}{|l|}{ Staging } \\
\hline Missing & $4(17.4)$ \\
\hline 1 & $1(4.3)$ \\
\hline 2 & $5(21.7)$ \\
\hline 3 & $7(30.4)$ \\
\hline 5 & $6(26.1)$ \\
\hline \multicolumn{2}{|c|}{ Initial ECOG performance status (PS) } \\
\hline Missing & $2(8.7)$ \\
\hline 0 & $14(60.9)$ \\
\hline 1 & $7(30.4)$ \\
\hline \multicolumn{2}{|c|}{ End of treatment ECOG PS } \\
\hline Missing & $3(13.0)$ \\
\hline 0 & $3(13.0)$ \\
\hline 1 & $16(69.6)$ \\
\hline 2 & $1(4.3)$ \\
\hline \multicolumn{2}{|c|}{ ECOG PS change (end versus baseline) } \\
\hline Missing & $5(21.7)$ \\
\hline Better & $1(4.3)$ \\
\hline Same & $6(26.1)$ \\
\hline Worse & $11(47.8)$ \\
\hline \multicolumn{2}{|c|}{ Number of eligibility items qualified* } \\
\hline 1 & $12(52.2)$ \\
\hline 2 & $9(39.1)$ \\
\hline 3 & $2(8.7)$ \\
\hline \multicolumn{2}{|c|}{ Qualified for criterion (1) } \\
\hline Yes & $10(43.5)$ \\
\hline No & $13(56.5)$ \\
\hline \multicolumn{2}{|c|}{ Qualified for criterion (2) } \\
\hline Yes & $10(43.5)$ \\
\hline No & $13(56.5)$ \\
\hline \multicolumn{2}{|c|}{ Qualified for criterion (3) } \\
\hline Yes & $15(65.2)$ \\
\hline No & $8(34.8)$ \\
\hline \multicolumn{2}{|c|}{ Qualified for criterion (4) } \\
\hline Yes & $1(4.3)$ \\
\hline No & $22(95.7)$ \\
\hline \multicolumn{2}{|c|}{ Ulceration of primary } \\
\hline Yes & $8(34.8)$ \\
\hline No & $12(52.2)$ \\
\hline Unknown & $3(13.0)$ \\
\hline \multicolumn{2}{|l|}{ Primary site } \\
\hline Ant trunk & $6(26.1)$ \\
\hline $\mathrm{H} / \mathrm{N}$ & $3(13.0)$ \\
\hline
\end{tabular}

TABle 1: Continued.

\begin{tabular}{|c|c|}
\hline & $n(\%)$ \\
\hline Pos trunk & $4(17.4)$ \\
\hline Upper ext & $4(17.4)$ \\
\hline Unknown & $6(26.1)$ \\
\hline \multicolumn{2}{|l|}{ Primary tumor thickness } \\
\hline Unknown & $2(8.7)$ \\
\hline Breslow $\leq .75$ Clark II & $8(34.8)$ \\
\hline Breslow .76-1.5 Clark III & $5(21.7)$ \\
\hline Breslow 1.51-4.0 Clark IV & $7(30.4)$ \\
\hline Breslow $>4.0$ Clark V or satellite & $1(4.3)$ \\
\hline \multicolumn{2}{|l|}{ Nodal site } \\
\hline Axilla & $16(69.6)$ \\
\hline Groin & $4(17.4)$ \\
\hline Neck & $3(13.0)$ \\
\hline \multicolumn{2}{|l|}{ Number of positive nodes } \\
\hline Missing & $1(4.3)$ \\
\hline $0-3$ & $13(56.5)$ \\
\hline $4-10$ & $4(17.4)$ \\
\hline$>10$ & $5(21.7)$ \\
\hline \multicolumn{2}{|l|}{ Nodal involvement } \\
\hline Missing & $1(4.3)$ \\
\hline No regional LN & $1(4.3)$ \\
\hline $\begin{array}{l}1 \text { regional station, node(s) mobile and } \\
\text { diameter } 3 \mathrm{~cm}\end{array}$ & $7(30.4)$ \\
\hline 1 lymph node station, diameter $>3 \mathrm{~cm}$ or fixed & $14(60.9)$ \\
\hline
\end{tabular}

${ }^{*}$ See Section 2.1.

a significant number of patients with palpable lymphadenopathy will recur in the dissected basin [4]. Most of these patients will go on to die of disseminated disease but often suffer with symptomatic regional disease until death. Prevention of local and regional failure could significantly improve the quality of life for these patients.

In the late 1990s, the introduction of interferon alfa-2b (IFN $\alpha$-2b) changed the management of patients with highrisk disease. Kirkwood et al. reported a phase III randomized trial of adjuvant postoperative IFN $\alpha$-2b which demonstrated a substantial survival advantage in patients with nodal involvement (overall survival was improved from 2.8 to 3.8 years) [5]. This was the first trial to show a significant benefit from adjuvant systemic therapy and in 1997 stimulated our group to open the long-term study presented here. In the meantime, the data from two subsequent Eastern Cooperative Oncology Group (ECOG) randomized trials have suggested that while adjuvant IFN $\alpha$-2b has biologic activity with a significant increase in disease-free survival rates, improvement in overall survival rates have not been as robust $[6,7]$.

The role of radiotherapy (RT) in the curative management of melanoma has also been controversial. Initial pilot data from multiple institutions had suggested that postoperative treatment with RT in high-risk patients could 
substantially reduce the local regional recurrence rate in stage III melanoma $[8,9]$. Indeed, postoperative RT has been employed in various fractionation schemes, including $48 \mathrm{~Gy}$ in 20 fractions 5 days per week and $30 \mathrm{~Gy}$ in 5 fractions over 2-1/2 weeks (total dose $3000 \mathrm{cGy}$ ). RT is usually begun approximately 3-6 weeks after surgery once wounds are sufficiently healed. Recent phase III randomized data investigate the efficacy of adjuvant RT in stage III melanoma patients randomly assigned to RT $(n=109)$ with $48 \mathrm{~Gy}$ in 20 fractions, or observation $(n=109)$ [10]. With a median follow-up of 27 months, the local disease relapse rate for RT and observation was $18 \%$ and $31 \%$, respectively, $(P=0.041)$. The median survival time for radiotherapy and observation was 2.6 years and 3.9 years $(P=0.14)$. There were no differences in toxicity between lymph node fields irradiated; no patients suffered from grade four toxicities.

The suggestion of potential benefit of RT and IFN $\alpha$ $2 \mathrm{~b}$ in similar high-risk patients raised the question of how best to integrate these treatments in the postoperative setting. Indeed, concurrent integration of IFN $\alpha$-2b immunotherapy with RT would avoid a delay of one of these modalities if given sequentially. In particular, a potential delay of IFN $\alpha$ $2 \mathrm{~b}$ for $6-8$ weeks to allow recovery from surgery and RT may reduce the effectiveness of this systemic agent.

Information is lacking describing RT given concurrently with IFN $\alpha-2 b$ in patients with advanced melanoma. Thus, the purpose of this study was to (1) evaluate the acute and late toxicity of post-operative hypofractionated RT given concurrently with IFN $\alpha-2 b$ to patients with extensive nodal involvement, (2) evaluate the effectiveness preventing regional recurrence of RT given concurrently with IFN $\alpha-2 \mathrm{~b}$ in such patients, and (3) provide feasibility and toxicity data for a potential subsequent randomized trial to determine the overall value of this intervention.

\section{Methods}

This work was approved by the Institutional Review Board at the University of South Florida/H. Lee Moffitt Cancer Institute. This is a prospective multi-center phase I/II study conducted to evaluate the acute and long term toxicity and efficacy of hypofractionated RT with concurrent IFN $\alpha-2 b$. Centers that enrolled patients included H. Lee Moffitt Cancer Center, Tampa, Florida, and the Sylvester Comprehensive Cancer Center, University of Miami, Miami, Florida.

2.1. Patient Selection. Patient inclusion criteria included stage III nodal disease involving the axilla, neck, or groin characterized as "advanced" based on one or more of the following characteristics: (1) four or more positive nodes, (2) a single node $\geq 4 \mathrm{~cm}$, (3) extracapsular disease involving $>10 \%$ of capsule circumference, or (4) soft tissue deposits in a nodal basin after previous lymphadenectomy. In addition, patients had to have all gross disease completely resected, no distant metastases present, no contraindications to radiation therapy, ECOG performance status 0-1, and life expectancy $>6$ months. Recurrent stage III disease was eligible for the study.
TABle 2: (a) Number of patients experiencing high grade ( $\mathrm{Gr}$ 3-4) interferon-related hematologic toxicity during any phase of therapy $(n=23)$. (b) Number of patients with high grade (Gr 34) interferon-related non-hematologic toxicity reported during any phase of therapy $(n=23)$.

(a)

\begin{tabular}{lcc}
\hline & Gr 3 & Gr 4 \\
\hline Hematologic & & \\
Leukopenia & 7 & 2 \\
Thrombocytopenia & 1 & 0 \\
Lymphocytopenia & 4 & 7 \\
Leukopenia w/fever & 2 & 0 \\
\hline
\end{tabular}

(b)

\begin{tabular}{|c|c|c|}
\hline & Gr 3 & Gr 4 \\
\hline \multicolumn{3}{|l|}{ Renal } \\
\hline Renal failure & 0 & 1 \\
\hline \multicolumn{3}{|l|}{ Gastrointestinal } \\
\hline Elevated LFTs & 7 & 0 \\
\hline Vomiting & 1 & 0 \\
\hline Nausea & 2 & 0 \\
\hline Gallstones & 1 & 0 \\
\hline \multicolumn{3}{|l|}{ Neurologic } \\
\hline Ataxia & 1 & 0 \\
\hline Dizziness & 1 & 0 \\
\hline TIA & 1 & 0 \\
\hline Pain & 2 & 0 \\
\hline Anxiety & 1 & 0 \\
\hline Depression & 4 & 0 \\
\hline \multicolumn{3}{|l|}{ Constitutional } \\
\hline Weight loss & 2 & 0 \\
\hline Fatigue & 4 & 0 \\
\hline Chills and fever & 1 & 0 \\
\hline \multicolumn{3}{|l|}{ Skin } \\
\hline Rash & 4 & 0 \\
\hline Pruritis & 1 & 0 \\
\hline Erythema & 1 & 0 \\
\hline \multicolumn{3}{|l|}{ Ocular } \\
\hline Cotton wool & 2 & 0 \\
\hline Ulcerated & 1 & 0 \\
\hline Other ocular toxicity & 2 & 0 \\
\hline \multicolumn{3}{|l|}{ Cardiac } \\
\hline Chest pain & 1 & 0 \\
\hline \multicolumn{3}{|l|}{ Pulmonary } \\
\hline Shortness of breath & 1 & 0 \\
\hline
\end{tabular}

2.2. Surgical Oncology Considerations. Definitive surgery included wide excision of the primary and complete lymphadenectomy prior to entry into the study. Wide excision with a minimum $1 \mathrm{~cm}$ margin surrounding the primary lesion or biopsy scar was required for entry onto this protocol. Excisions included skin and all subcutaneous tissue 
TABLE 3: Worst acute toxicity at 2 weeks post concurrent RT $(n=$ 23).

\begin{tabular}{lcc}
\hline & Skin & Mucosa \\
\hline RTOG & & \\
Acute toxicity grade & 14 & 2 \\
1 & 7 & 1 \\
2 & 2 & 0 \\
3 & 0 & 0 \\
4 & 23 & 3 \\
\hline Total & 23 \\
\hline
\end{tabular}

TABle 4: Number of patients experiencing high-grade (Gr 3-4) late toxicity $(n=11)$.

\begin{tabular}{lcc}
\hline Toxicity & Gr 3 & Gr 4 \\
\hline & 0 & $1^{*}$ \\
Skin & 0 & 0 \\
Subcutaneous fibrosis & 0 & 0 \\
Joint & 0 & 0 \\
Lymphedema & 0 & $1^{*}$ \\
Brachial plexopathy & &
\end{tabular}

* One patient same arm.

down to the muscular fascia. Fascia was included at the discretion of the operating surgeon. Closure of the defect was via primary closure, split thickness skin graft, or rotation flap at the discretion of the surgeon.

For regional lymphadenectomy, all patients underwent one of the following lymphadenectomies: (1) head and neck lesions (to yield a minimum of 15 nodes), face, ear, and anterior scalp: parotidectomy plus modified radical neck or radical neck dissection, posterior scalp: modified radical or radical neck dissection plus suboccipital nodes; (2) upper extremity (to yield a minimum of 10 nodes), axillary node dissection to include at least 10 nodes taken from level I and II, with level III nodes dissected if they were clinically involved and the pectoralis minor muscle was divided or sacrificed at the surgeon's discretion; and (3) lower extremity (to yield a minimum of 5 nodes); superficial inguinal node dissection was required with a deep inguinal node dissection at the discretion of the surgeon.

2.3. Medical Oncology Considerations. Induction IFN $\alpha-2 b$, $20 \mathrm{MU} / \mathrm{m}^{2} / \mathrm{d}$, was administered intravenous $\times 5$ consecutive days out of 7 (Monday-Friday) every week for 4 weeks. Next, RT consisting of $30 \mathrm{~Gy} / 5$ fractions (6 Gy per fraction twice-aweek on Tuesdays and Thursdays) was given with concurrent IFN $\alpha-2 b, 10 \mathrm{MU} / \mathrm{m}^{2}$ SQ 3 times per week (Monday, Wesnesday, Friday) on days alternating with RT. Finally, patients underwent consolidation/maintenance therapy with adjuvant IFN $\alpha-2 b, 10 \mathrm{MU} / \mathrm{m}^{2}$ SQ 3 times per week for the remainder of 1 year.

Patients received their first injection of IFN $\alpha-2 \mathrm{~b}$ within 3 business days of study entry. Actual weight was used when calculating body surface area. Corticosteroids and other immunosuppressive medications were contraindicated because of immune suppressive effects. Patients who were deemed competent to self-administer the subcutaneous maintenance doses of IFN $\alpha$-2b did so following the first 4 weeks of treatment. Dose modification criteria required the holding of treatment until return to institution's normal limits or patient's baseline. A 33\% reduction of dosage occurred after first treatment interruption and a 66\% reduction (of the original dose) after the second treatment interruption for toxicity. This was a permanent reduction. A patient who required a third dose modification was removed from treatment. Dose reescalation was not attempted following resolution of toxicity that required dose interruption or attenuation.

2.4. Radiation Oncology Considerations. RT commenced after 4 weeks of high-dose intravenous IFN $\alpha$-2b therapy. Therapy alternated days with IFN $\alpha-2 \mathrm{~b}$ (RT on Tuesday and Thursday with IFN $\alpha-2 \mathrm{~b}$ on Monday, Wednesday, and Friday) to a total of $30 \mathrm{~Gy}$ in five fractions in 2-1/2 weeks. With respect to treatment planning, treatment was given with electrons whenever feasible. The electron energy was appropriate for the depth of the tumor and surgical bed. Photons were used in selected cases, for example, opposed or 10 degree oblique parallel-opposed axillary fields, or mixed beam to the inguinal area. CT-based treatment planning was used to limit the volume of normal tissue in-field. Field borders were generally confined to the dissected nodal bed with approximately $2-3 \mathrm{~cm}$ margins. There was no intent to treat large elective volumes of undissected tissue (i.e., supraclavicular fossa or pelvis). Bolus was used to prevent under dosage to tumor bed when photons and low-energy electrons $(\leq 6-9 \mathrm{MeV})$ were used. Tissue heterogeneity corrections for lung were used. Isodose distributions were performed at multiple levels, generally every $3-5 \mathrm{~cm}$. Inhomogeneity did not exceed a $5 \%$ hot spot or a $10 \%$ cold spot across the target volume. This allowed for a maximum 15\% point gradient across the target volume. For treatment of groin or axilla, dose was calculated to the $D$ max anteriorly which often results in dose to the deep axilla which was $5-8 \%$ less than the $D$ max dose. The junction between the abutting fields was moved $1 \mathrm{~cm}$ after the $2 \mathrm{nd}$ and 4 th treatments to prevent dose inhomogeneity and thus minimize the risk of fibrosis. Avoidance of critical structures was undertaken, and the maximum permissible dose to the spinal cord was $24 \mathrm{~Gy}$ and $30 \mathrm{~Gy}$ to the brachial plexus or femoral nerve.

2.5. Follow-Up. To establish the presence of local recurrence follow-up continued for up to 10 years following treatment. Patients were seen monthly during interferon therapy, then every 3 months for 1 year, every 6 months up to the end of year 5 , and then annually thereafter.

2.6. Statistical Considerations. The study was designed primarily to evaluate in a preliminary fashion the toxicity and effectiveness of postoperative hypofractionated radiotherapy given concurrently with interferon $\alpha$-2b to patients with advanced stage III melanoma, that is, those with extensive 
TABLE 5: Worst late toxicity post concurrent RT/IFN $(n=11)$.

\begin{tabular}{cccccc}
\hline RTOG Acute Grade & Skin atrophy & Fibrosis & Joint motion & Lymphedema & Neuritis \\
\hline 1 & 5 & 2 & 3 & 0 & 1 \\
2 & 1 & 3 & 3 & 0 & 1 \\
3 & 0 & 0 & 0 & 0 & 0 \\
4 & 1 & 0 & 0 & 6 & 3 \\
\hline Total & 7 & 5 & 6 & 1 \\
\hline
\end{tabular}

TABLE 6: Patterns of failure among all evaluable patients $(n=23)$.

\begin{tabular}{lcc}
\hline & Number & $\%$ \\
\hline NED overall & 7 & 30.4 \\
In-field failure only & 3 & 13.0 \\
In-field + distant & 1 & 4.3 \\
Out-field failure only & 0 & 0 \\
Out-field + distant & 0 & 0 \\
Distant failure only & 11 & 47.8 \\
Unknown status & 1 & 4.3 \\
\hline Regional control & 18 & 78.3 \\
Regional recurrence & 5 & 21.7 \\
\hline TOTAL & 23 & 100 \\
\hline
\end{tabular}

nodal involvement, in preventing regional recurrence. Sites of nodal disease were stratified according to location: neck, axilla, or groin. Fifteen treated cases were the planned accrual goal for each of these 3 cohorts. A total of 50 cases enrolled would account for an approximate 10\% loss to follow-up rate.

Kaplan-Meier estimates of the regional failure rates at desired time points were calculated along with 95\% confidence intervals. With one year of postaccrual follow-up and approximately 50 eligible cases accrued over 2.75 years, the standard error for the two-year estimate would be 0.05 if that estimate was 0.1 and 0.07 if it was 0.2. An estimate and $95 \%$ confidence interval for the toxicity rate would also be calculated when appropriate. If that rate was $20 \%$ or less, the width of the confidence interval would not exceed $22 \%$.

This study also stipulated that the trial would be flagged for early termination if four or more of the first fifteen patients experience a grade 3 or greater acute or late toxicity. The probability of this was $83 \%$ if the toxicity rate was $35 \%$ and $6 \%$ if the toxicity rate was $10 \%$. A total of 29 consenting patients were registered to this trial.

Time to regional failure (TRF) was calculated from the start of treatment to the date of regional failure. Overall survival (OS) was calculated from the start of treatment to the date of death. Similarly, the failure-free survival (FFS) was defined as time from the start of treatment to the date of death or (distant or regional) failure, whichever occured first. All these time-to-event endpoints were censored at the last follow-up time, if no relevant event(s) had happened by that date. The Kaplan-Meier method was used for analysis of these endpoints. Whenever feasible, both the point estimate and its $95 \%$ confidence interval (CI) of the median event time were also reported. In the case of TRF, the competing risks issue due to death was also considered and alternative methodology was used to take that into consideration. Nonetheless, the Kaplan-Meier approach and competing risks approach yielded very similar results, mostly due to the fact that there was only one competing event, that is, death, prevented regional failure, the event of interest, from happening prior to the last occurrence of regional failure in this study. Therefore the results using the competing risks approach were omitted from this report. The statistical analyses were performed using the SAS statistical software (version 9.1; SAS Institute Inc., Cary, North Carolina).

\section{Results}

A total of 29 consenting patients were enrolled between August 1997 and March 2000. Six patients did not receive RT (1 ineligible, 1 for technical reasons, 1 withdrew consent, 3 due to high-dose induction IFN $\alpha$-2b toxicity). Twenty-three of 29 patients $(80 \%)$ received full therapy. Radiation therapy was directed to the axillary node basin in 16, the groin in 4 , and the neck in 3 patients. Due to small numbers of the groin and neck patients, all data analyses were done pooling all patients together. Demographic baseline data with respect to the patients are seen in Table 1.

The number of patients experiencing high-grade ( $\mathrm{Gr} 3-4)$ IFN $\alpha$-2b-related hematologic and nonhematologic toxicity reported during any phase of therapy is seen in Table 2(a) and Table 2(b), respectively. The maximum (worst) grade of acute radiation toxicity during concurrent RT/IFN $\alpha-2 b$ (and up to 2 weeks post RT) was grade 3 skin toxicity noted in 2 patients (9\%, Table 3 ).

With respect to late toxicity, no patient experienced a grade 3 toxicity (Tables 4 and 5). Only one patient developed a grade 4 toxicity. This occurred in a 59-yearold man with known herniated disc disease who developed a brachial plexopathy resulting in partial disability of the limb. It occurred following 3 cycles of bio-chemotherapy for recurrence in the axilla. Indeed, he developed difficulty raising the left arm above 60 degrees with numbness and tingling in the ulnar distribution and contracture of his palm and fingers. There were minimal grade 1 and 2 late radiation toxicities following concurrent RT/IFN $\alpha$-2b including skin telangiectasia, subcutaneous fibrosis, limitation in joint motion, and lymphedema (Table 4).

With respect to effectiveness, the regional recurrence rate was $22 \%$ (95\% CI: $55 \%-90 \%)$ at 12 months (Table 6). The median follow-up (range) was 80 (51-106) months among 


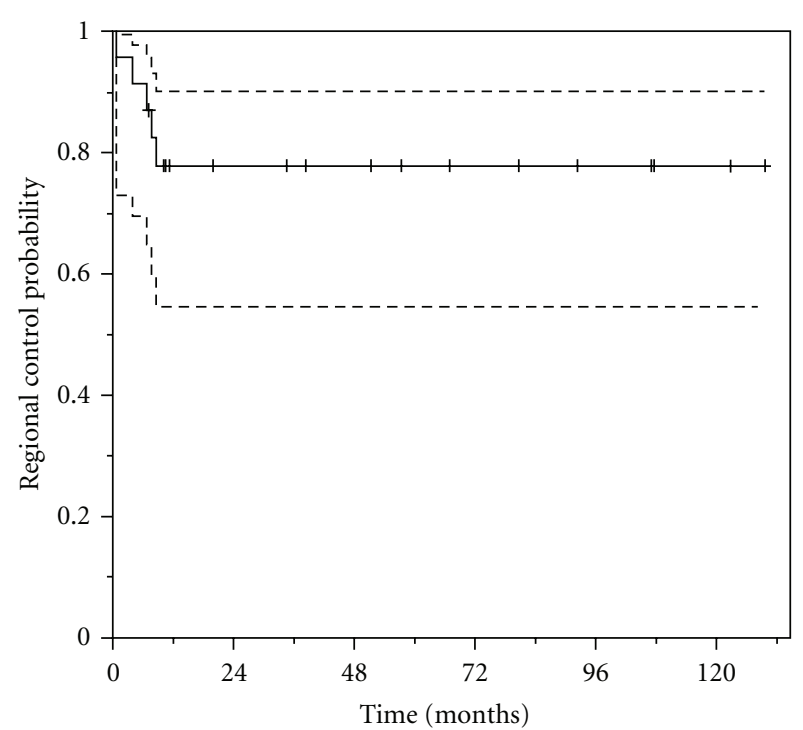

Figure 1: Kaplan-Meier curve and pointwise confidence intervals for local regional control $(n=23)$ : 5 (22\%) local regional failures.

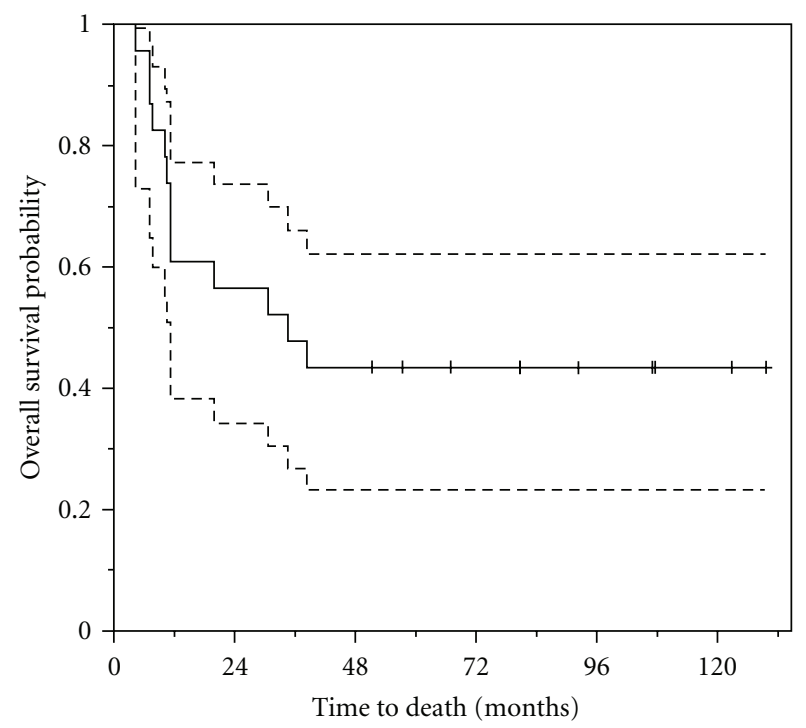

Figure 2: Kaplan-Meier curve and pointwise confidence intervals for overall survival $(n=23)$ : $13(57 \%)$ deaths; median OS = 34.5 months.

ten survivors (43\%); they were last seen alive at 51, 51, 66, $69,82,93,95,103,113$, and 117 months, respectively. The Kaplan-Meier curve and its pointwise confidence intervals for local regional control are seen in Figure 1 while the Kaplan-Meier curves and their pointwise confidence intervals for overall survival and failure-free survival are seen in Figures 2 and 3, respectively. The median overall survival was 34.5 months while the median failure-free survival was 19.9 months (including either distant or regional failure or death as events). Table 7 lists estimated OS or FFS probabilities at various time points of interest along with corresponding $95 \%$ CIs.

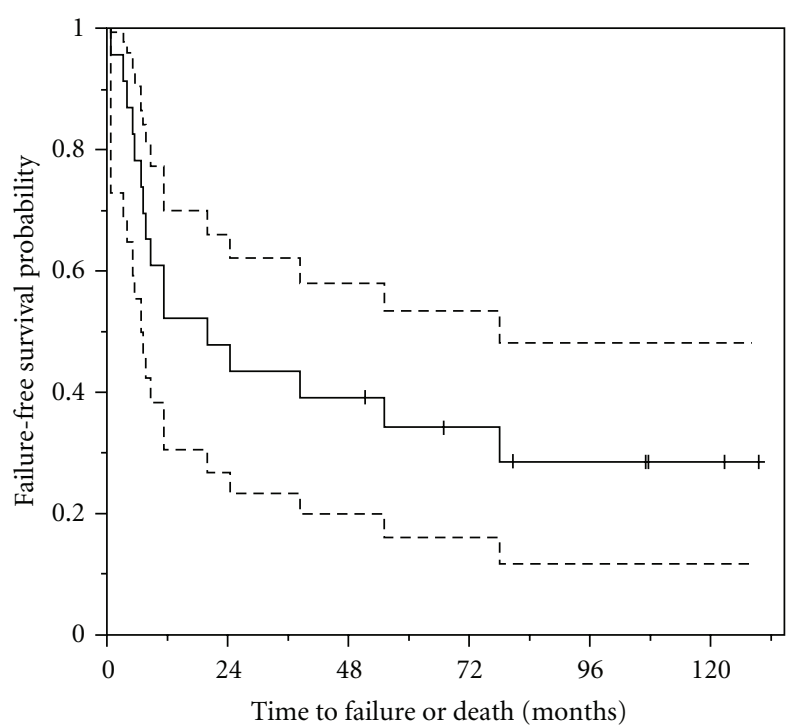

FIGURE 3: Kaplan-Meier curve and pointwise confidence intervals for disease-free/failure-free survival $(n=23): 16(70 \%)$ distant or local regional failures or deaths; median (95\% CI) FFS = 19.9 (7.7, 78.0) months.

\section{Discussion}

Adjuvant therapy is widely used in melanoma cases because recurrence of disease following surgical extirpation can be difficult to treat and usually results in the patient's death $[5,8]$. Decisions regarding adjuvant therapy are based on features of the primary melanoma and status of the sentinel nodes. The mainstay for adjuvant therapy for stage III high-risk melanoma remains interferon therapy for systemic and local benefits, and adjuvant radiation for local control $[5,8]$.

IFN $\alpha-2 b$ is the only US Food and Drug Administration(FDA-) approved adjuvant regimen for patients with stage IIB and stage III melanoma and is considered standard of care for these patients in the United States. The Eastern Cooperative Oncology Group (ECOG) trial E1684 was the first randomized, placebo-controlled study of high-dose IFN $\alpha$-2b (HDI) in 287 patients with stage IIb $(n=31)$ or stage III melanoma [5]. At initial publication after a median follow-up time of 6.9 years, relapse-free survival (RFS) increased from 1.0 to 1.7 years, and overall survival (OS) increased from 2.8 to 3.8 years, both of which were statistically significant [5]. Updated results after initiation of our study with a very long median follow-up of 12.6 years showed the RFS benefit to have been maintained, but the statistical significance of the survival benefit had been lost [19]. ECOG trial E1690 accrued 642 patients to a 3-arm study comparing HDI $(n=215)$ to low-dose interferon (LDI; 3 MU 3 times per week for 2 years, $n=215$ ) to observation $(n=215)$. HDI showed an improvement in RFS (44\% relapse-free at 5 years) compared to LDI and observation (40\% and 35\%, respectively). However, unlike ECOG trial E1684, no OS benefit was seen with either HDI or LDI compared to observation [6]. A third study, ECOG 
TABLE 7: Estimated overall survival and failure-free survival probabilities at time points of interest along with corresponding 95\% CIs $(n=23)$.

\begin{tabular}{lcccc}
\hline At Time (months) & OS Probability & $95 \%$ CI & FFS Probability & $95 \%$ CI \\
\hline 6 & 0.96 & $0.73-0.99$ & 0.78 & $0.55-0.90$ \\
12 & 0.61 & $0.38-0.77$ & 0.52 & 0.48 \\
24 & 0.57 & $0.34-0.74$ & 0.43 & $0.27-0.66$ \\
36 & 0.48 & $0.27-0.66$ & $0.23-0.62$ \\
\hline
\end{tabular}

TABLE 8: Review of retrospective literature on combination of RT and IFN $\alpha$-2b for nonmelanoma.

\begin{tabular}{|c|c|c|c|c|}
\hline Study & Site & Systemic agents & Radiation & Outcome \\
\hline Maasilta et al. $[11,12]$ & lung cancer $n=10$ & $\begin{array}{l}\text { cisplatin and etoposide } \\
\text { combined with IFN } \alpha-2 \mathrm{~b} \text { at } \\
3 \text { million units IM as well } \\
\text { as } 1.5 \text { million units by jet } \\
\text { inhaler nebulizer }\end{array}$ & $\begin{array}{l}1.25 \text { Gy given twice/day } \\
\text { to a total dose of } 60 \text { Gy }\end{array}$ & $\begin{array}{l}\text { severe esophagitis } \\
(n=4)\end{array}$ \\
\hline Hoffmann et al. [13] & lung cancer $n=6$ & $\begin{array}{l}\text { cis-retinoic acid with IFN } \\
\alpha \text {-2b } 3 \text { million units } \\
\text { subcutaneous } 3 \text { times/wk }\end{array}$ & 50-70 Gy over 5-7 weeks & mucositis $20-50 \%$ cases \\
\hline Selman et al. [14] & lung cancer $n=38$ & $\begin{array}{l}\text { IFN } \alpha \text {-2b } 6 \text { million } \\
\text { units/day for } 5 \text { days before } \\
\text { radiation therapy and } 3 \\
\text { million units } 4 \text { days } \\
\text { afterwards }\end{array}$ & 55-60 Gy & $\begin{array}{l}\text { response } 10 / 26 \text { in those } \\
\text { receiving IFN } \alpha \text {-2b with } \\
\text { toxicity of less fibrosis } \\
\text { and more pneumonitis }\end{array}$ \\
\hline Stevens et al. [15] & lung cancer $n=6$ & $\begin{array}{l}\text { IFN } \alpha \text {-2b } 2 \text { million units } \\
\text { subcutaneously } 3 \\
\text { times/week }\end{array}$ & 54-66 Gy & no appreciable benefit \\
\hline Verastegui et al. [16] & cervix $n=18$ & $\begin{array}{l}5 \text { million units } \\
\text { subcutaneously } 3 \\
\text { times/week of IFN } \alpha-2 b\end{array}$ & $\begin{array}{l}\text { extracavitary and } \\
\text { intracavitary radiation, } \\
6-10 \mathrm{~Gy}\end{array}$ & $\begin{array}{l}\text { five year survival } 28 \% \\
\text { compared to } 7 \% \text { in the } \\
\text { control group; } 94 \% \text { of } \\
17 \text { patients developed } \\
\text { proctitis requiring } \\
\text { colostomy }\end{array}$ \\
\hline Rahn et al. [17] & cervix $n=4$ & $\begin{array}{l}\text { IFN } \alpha \text { - } 2 \text { b, } 3 \text { million units } \\
\text { subcutaneously } 3 \\
\text { times/week as well as } \\
\text { cis-retinoic acid }\end{array}$ & various & $\begin{array}{l}25 \% \text { Grade } 3 \\
\text { desquamation and } \\
\text { erythema }\end{array}$ \\
\hline Antonadou et al. [18] & cervix & $\begin{array}{l}3 \text { million units/day of IFN } \\
\alpha-2 b \text { and } 13 \text {-cis retinoic } \\
\text { acid }\end{array}$ & various & "well tolerated" \\
\hline
\end{tabular}

E1694, accrued 880 patients and compared an investigational ganglioside vaccine with HDI. HDI demonstrated a statistically significant benefit compared to the vaccine in terms of RFS and OS [7]. This raised the question of whether HDI led to benefit or the vaccine caused harm, a question that has gained additional credence after a randomized trial of the same vaccine compared to observation in patients with stage II melanoma was stopped early because of a possible decrease in survival for vaccine-treated patients in the face of definite evidence of no impact on RFS [20]. With more than 2,000 patients treated on clinical trials of adjuvant HDI, it is clear that HDI delays recurrences and improves diseasefree survival although the magnitude of these benefits is not optimal [21].

Multiple retrospective series have reported improvements following postoperative radiotherapy in regional control to the resected nodal basin at high risk for subsequent failure [26-28]. These studies have consistently shown risk factors to include multiple positive nodes ( $\geq 3$ nodes), large nodal size $(\geq 3 \mathrm{~cm})$, extracapsular extension (ECE), and/or recurrent disease, with combinations of these factors conferring the greatest risk. Recently, prospective data have been reported from Australia that demonstrate improved regional control with adjuvant radiation therapy in patients with positive nodes, large nodes, and/or ECE [10]. This study was presented at the 2009 annual meeting of the American Society for Radiation Oncology as a plenary session. Inclusion criteria for this trial included any of 1 or more parotid, 2 or more cervical or axillary, or 3 or more positive groin nodes; ECE; at least a $3-\mathrm{cm}$ node positive in the head and neck or axilla; or a $4-\mathrm{cm}$ node in the axilla. After lymphadenectomy, patients were randomized to receive either radiation therapy ( $48 \mathrm{~Gy}$ in 20 fractions) to the regional nodal field or observation. Regional relapse as a first 
TABLE 9: Review of retrospective literature on combination of RT and IFN $\alpha$-2b for melanoma.

\begin{tabular}{|c|c|c|c|c|}
\hline Study & Site & Regimen & Radiation & Outcome \\
\hline Hazard et al. [22] & melanoma $n=10$ & $\begin{array}{l}\text { concurrent or within } 1 \\
\text { month }\end{array}$ & $45-50 \mathrm{~Gy}$ & $\begin{array}{l}\text { 5/10 severe subacute/late } \\
\text { complications including two } \\
\text { patients with peripheral } \\
\text { neuropathy, one patient with } \\
\text { radiation necrosis in the brain, } \\
\text { and two patients with radiation } \\
\text { necrosis in the subcutaneous } \\
\text { tissue. }\end{array}$ \\
\hline Conill et al. [23] & melanoma $n=18$ & $\begin{array}{l}\text { concurrent or within } 1 \\
\text { month }\end{array}$ & $\begin{array}{l}30 \text { Gy/5 fractions } \\
(n=8), 36 \mathrm{~Gy} / 6 \\
\text { fractions }(n=8) \\
50 \text { Gy/25 fractions } \\
(n=2)\end{array}$ & $\begin{array}{l}\text { FFS at } 3 \text { years was } 88 \% \text {. All the } \\
\text { patients experienced grade I } \\
\text { acute skin reactions. Late toxicity } \\
\text { was seen in one patient with } \\
\text { grade III (RTOG) skin reaction } \\
\text { and two with grade IV (RTOG) } \\
\text { radiation-induced myelitis. }\end{array}$ \\
\hline Gyorki et al. [24] & melanoma $n=18$ & concurrent & $\begin{array}{l}40-50 \text { Gy in } 15-25 \\
\text { fractions }\end{array}$ & $\begin{array}{l}\text { 7/18 grade } 3 \text { skin reactions. } \\
\text { Severe radiation-induced toxicity } \\
\text { was seen in three patients, one } \\
\text { who developed radiation } \\
\text { pneumonitis, one who developed } \\
\text { severe oral mucositis, and one } \\
\text { who developed wound } \\
\text { dehiscence. }\end{array}$ \\
\hline Nguyen et al. [25] & melanoma $n=3$ & concurrent & 41.4-66 Gy & $\begin{array}{l}\text { All three patients achieved local } \\
\text { control at } 24,18 \text { and } 19 \text { months } \\
\text { followup; one patient developed } \\
\text { widespread distant metastases. }\end{array}$ \\
\hline
\end{tabular}

relapse was the primary end point. Patients $(n=250 ; 123$ in the radiation arm and 127 in the observation arm) from 2002 to 2007 were randomized from 16 centers. Although overall survival was not different, this study showed a statistically significant improvement in lymph node field control with the addition of radiotherapy: 20 patients in the radiation arm versus 34 patients in the observation $\operatorname{arm}(P=0.041)$ [10]. Although these emerging data help confirm the role of radiotherapy in the adjuvant setting, integration with systemic treatment has never been prospectively tested until this study.

There is little published retrospective experience with concurrent radiation and IFN $\alpha-2 \mathrm{~b}$. Radiation has been given together with IFN $\alpha-2 \mathrm{~b}$ in a limited number of patients with carcinoma of the lung and cervix [11-18]. A summary of these studies is described in Table 8. Several small retrospective studies have recently been reported on the role of concurrent radiotherapy or interferon or radiotherapy within 1 month of the delivery of interferon in resected high-risk melanoma [22-25]. These studies have generally reported locoregional control rates to be comparable with historical rates (Table 9). However, despite small numbers of patients in these series, there has been concern over greater than expected late toxicity particularly soft tissue injury, lung injury, and myelitis.

Thus, in 1997 we established a prospective long-term trial of these combination of agents with careful monitoring of acute and late toxicity over $>10$ years with the belief that if long-term toxicity could be found to be acceptable, this treatment program could be then tested in a larger randomized trial to document efficacy. Although our target accrual goal was 50 patients, we were only able to enroll 29 patients. A significant reason included difficulties in enrolling patients as cooperative group data emerged showing less clear benefits in overall survival with the use of interferon. Additionally there was increasing concern amongst some investigators over possible late effects.

Our data suggest that the number of patients experiencing high-grade (Gr 3-4) interferon hematologic and nonhematologic toxicity reported during any phase of therapy is comparable with prior experience. What is remarkable is that the maximum (worst) grade of acute radiation toxicity during concurrent RT/IFN (and up to 2 weeks post RT) was quite low with grade 3 skin toxicity noted in 2 patients (9\%). In addition, at the median follow-up of more than 6 years among ten survivors, no patient experienced a grade 3 toxicity. Only one patient developed a grade 4 toxicity following 3 cycles of bio-chemotherapy for recurrence in axilla. Finally, grade 1 and 2 late radiation toxicities following concurrent RT/IFN were minimal including skin telangiectasia, subcutaneous fibrosis, limitation in joint motion, and lymphedema.

Despite these promising results, we no longer use this particular radiation fractionation schedule at our center due to concerns regarding potential late effects associated with large dose per fraction radiotherapy. Although the observed rate of late effects was acceptable, the power to detect true rates of late injuries is small in this pilot study. We now routinely use intensity-modulated radiation therapy (IMRT) for complex axillary and groin targets to improve 
homogeneity and to reduce the volume of normal tissue at risk for fibrosis or other injury.

\section{Summary}

In summary, these data suggest that post-operative concurrent hypofractionated RT and IFN for advanced stage III melanoma are associated with acceptable acute and late toxicity and provide reasonable in-field control in patients at high risk of regional failure. These data may be useful in advancing new concurrent radiation and bioimmunotherapy trials [29-32].

\section{Disclosure}

V. Sondak is a consultant for Merck/Schering-Plough. This paper presented in oral form at 50th Annual ASTRO Meeting, Boston, Massachusetts, and ASTRO Head and Neck Symposium, Chandler, Arizona.

\section{References}

[1] A. Jemal, R. Siegel, J. Xu, and E. Ward, "Cancer statistics, 2010," CA Cancer Journal for Clinicians, vol. 60, no. 5, pp. 277 $300,2010$.

[2] "Reporting of cancer survival and end results," in American Joint Committee on Cancer: Manual for Staging of Cancer, O. H. Beahrs and M. H. Myers, Eds., p. 117, J. B. Lippincott, Philadelphia, Pa, USA, 2nd edition, 1983.

[3] R. M. Byers, "The role of modified neck dissection in the treatment of cutaneous melanoma of the head and neck," Archives of Surgery, vol. 121, no. 11, pp. 1338-1341, 1986.

[4] C. M. Balch, S. Soong, T. M. Murad et al., "A multifactorial analysis of melanoma: IV. Prognostic factors in 200 melanoma patients with distant metastases (stage III)," Journal of Clinical Oncology, vol. 1, no. 2, pp. 126-134, 1983.

[5] J. M. Kirkwood, M. H. Strawderman, M. S. Ernstoff, T. J. Smith, E. C. Borden, and R. H. Blum, "Interferon $\alpha-2 b$ adjuvant therapy of high-risk resected cutaneous melanoma: the Eastern Cooperative Oncology Group trial EST 1684," Journal of Clinical Oncology, vol. 14, no. 1, pp. 7-17, 1996.

[6] J. M. Kirkwood, J. G. Ibrahim, V. K. Sondak et al., "High- and low-dose interferon $\alpha$-2b in high-risk melanoma: first analysis of intergroup trial E1690/S9111/C9190," Journal of Clinical Oncology, vol. 18, no. 12, pp. 2444-2458, 2000.

[7] J. M. Kirkwood, J. G. Ibrahim, J. A. Sosman et al., "Highdose interferon $\alpha$-2b significantly prolongs relapse-free and overall survival compared with the GM2-KLH/QS-21 vaccine in patients with resected stage IIB-III melanoma: results of intergroup trial E1694/S9512/C509801," Journal of Clinical Oncology, vol. 19, no. 9, pp. 2370-2380, 2001.

[8] K. K. Ang, R. M. Byers, L. J. Peters et al., "Regional radiotherapy as adjuvant treatment for head and neck malignant melanoma," Archives of Otolaryngology: Head and Neck Surgery, vol. 116, no. 2, pp. 169-172, 1990.

[9] A. Trotti and L. J. Peters, "The role of radiotherapy in the primary management of cutaneous melanoma," Annals of Plastic Surgery, vol. 28, no. 1, pp. 39-44, 1992.

[10] B. Burmeister, M. A. Henderson, J. F. Thompson et al., "Adjuvant radiotherapy improves regional (lymph node field) control in melanoma patients after lymphadenectomy: results of an intergroup randomized trial (TROG 02.01/ANZMTG
01.02)," International Journal of Radiation Oncology Biology Physics, vol. 75, supplement 3, p. S2, 2009.

[11] H. M. Maasilta, P. Maasilta, M. Hallman, and K. Mattson, "The effect of Interferon and radiation therapy on tumor response and radiation-induced lung injury in small cell lung cancer," American Journal of Respiratory and Critical Care Medicine, vol. 151, no. 4, p. 850, 1995.

[12] P. Maasilta, L. R. Holsti, M. Halme, L. Kivisaari, K. Cantell, and K. Mattson, "Natural alpha-interferon in combination with hyperfractionated radiotherapy in the treatment of non-small cell lung cancer," International Journal of Radiation Oncology Biology Physics, vol. 23, no. 4, pp. 863-868, 1992.

[13] W. Hoffmann, M. Schiebe, P. Hirnle et al., "13-cis retinoic acid and interferon- $\alpha+/$ - irradiation in the treatment of squamous-cell carcinomas," International Journal of Cancer, vol. 70, no. 4, pp. 475-477, 1997.

[14] E. Selman, P. Lopez-Saura, E. Neninger et al., "Multicenter randomized clinical trial of alpha Interferon and radiotherapy in non-operable non-small cell lung cancer," Journal of Interferon \& Cytokine Research, vol. 10, supplement 1, p. 132, 1990.

[15] C. Stevens, J. Torrisi, C. Berg et al., "The use of radiotherapy with alpha-2b Interferon sensitization in locally advanced unresectable non-small cell carcinima of the lung-a pilot study," in Proceedings of the American Society of Clinical Oncology (ASCO '90), Washington, DC, USA, May 1990.

[16] E. Verastegui, J. G. DeLa Garza, A. Mota et al., "Five year survival of patients with advanced stages IIIb/IV cervical carcinoma with combined treatment using radiation therapy and alpha $2 \mathrm{~b}$ Interferon," in Proceedings of the 5th International Congress on Anti-Cancer Chemotherapy, Paris, France, 1995.

[17] A. Rahn, S. Moss, I. A. Adamietz et al., "Pronounced dermatological side effects following irradiation (RT) given with interferon $\alpha$-2A (IFN) plus retinoic acid (RA)," European Journal of Cancer, vol. 31, supplement 6, p. S126, 1995.

[18] D. Antonadou, M. Synodinou, P. Iliopoulos, M. Katsoulis, and N. Throuvalas, "Combined radiotherapy and immunotherapy in advanced stages of cancer of the uterine cervix," European Journal of Cancer, vol. 31, supplement 6, p. S248, 1995.

[19] J. M. Kirkwood, J. Manola, J. Ibrahim, V. Sondak, M. S. Ernstoff, and U. Rao, "A pooled analysis of ECOG and Intergroup trials of adjuvant high-dose interferon for melanoma," Clinical Cancer Research, vol. 10, no. 5, pp. 1670-1677, 2004.

[20] A. M. M. Eggermont, "Immunotherapy: vaccine trials in melanoma-time for reflection," Nature Reviews Clinical Oncology, vol. 6, no. 5, pp. 256-258, 2009.

[21] K. Wheatley, N. J. Ives, and P. Lorigan, "Does adjuvant vaccine therapy really have activity in malignant melanoma?" Journal of Clinical Oncology, vol. 25, no. 29, pp. 4693-4695, 2007.

[22] L. J. Hazard, W. T. Sause, and R. D. Noyes, "Combined adjuvant radiation and interferon-alpha $2 \mathrm{~B}$ therapy in highrisk melanoma patients: the potential for increased radiation toxicity," International Journal of Radiation Oncology Biology Physics, vol. 52, no. 3, pp. 796-800, 2002.

[23] C. Conill, S. Jorcano, J. Domingo-Domènech et al., "Toxicity of combined treatment of adjuvant irradiation and interferon $\alpha 2 \mathrm{~b}$ in high-risk melanoma patients," Melanoma Research, vol. 17, no. 5, pp. 304-309, 2007.

[24] D. E. Gyorki, J. Ainslie, M. L. Joon, M. A. Henderson, M. Millward, and G. A. McArthur, "Concurrent adjuvant radiotherapy and interferon- $\alpha 2 \mathrm{~b}$ for resected high risk stage III melanoma-a retrospective single centre study," Melanoma Research, vol. 14, no. 3, pp. 223-230, 2004. 
[25] N. P. Nguyen, S. Sallah, C. Childress, M. R. Salehpour, and U. Karlsson, "Interferon- $\alpha$ combined with radiotherapy in the treatment of unresectable melanoma," Cancer Investigation, vol. 19, no. 3, pp. 261-265, 2001.

[26] B. A. Guadagnolo and G. K. Zagars, "Adjuvant radiation therapy for high-risk nodal metastases from cutaneous melanoma," The Lancet Oncology, vol. 10, no. 4, pp. 409-416, 2009.

[27] B. Beadle, A. Guadagnolo, M. Ballo et al., "Radiation therapy field extent for adjuvant treatment of axillary metastases from malignant melanoma," International Journal of Radiation Oncology Biology Physics, vol. 73, no. 5, pp. 1376-1382, 2009.

[28] D. Chang, R. Amdur, C. G. Morris, and W. M. Mendenhall, "Adjuvant radiotherapy for cutaneous melanoma: comparing hypofractionation to conventional fractionation," International Journal of Radiation Oncology Biology Physics, vol. 66, no. 4, pp. 1051-1055, 2006.

[29] S. E. Finkelstein, D. M. Heimann, C. A. Klebanoff et al., "Bedside to bench and back again: how animal models are guiding the development of new immunotherapies for cancer," Journal of Leukocyte Biology, vol. 76, no. 2, pp. 333-337, 2004.

[30] S. E. Finkelstein, D. Gabrilovich, M. Bui et al., "Combination of External Beam Radiation (EBRT) with intratumoral injection of dendritic cells as neo-adjuvant treatment of high-risk soft tissue sarcoma patients," International Journal of Radiation Oncology Biology Physics, vol. 82, no. 2, pp. 924-932, 2012.

[31] S. E. Finkelstein, F. Rodriguez, M. Dunn et al., "Knowing when to say when: prospective serial assessment of apoptosis, cell death, and lymphocyte infiltrates during the first clinical experience with intraprostatic autologous dendritic cell injection coordinated with radiation therapy," Immunotherapy. In press.

[32] S. E. Finkelstein, R. Timmerman, W. H. McBride et al., "The confluence of stereotactic ablative radiotherapy and tumor immunology," Clinical and Developmental Immunology, vol. 2011, Article ID 439752, 7 pages, 2011. 


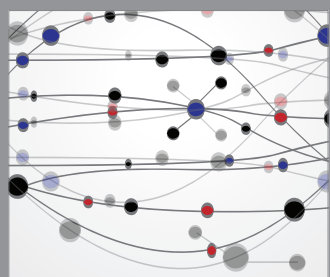

The Scientific World Journal
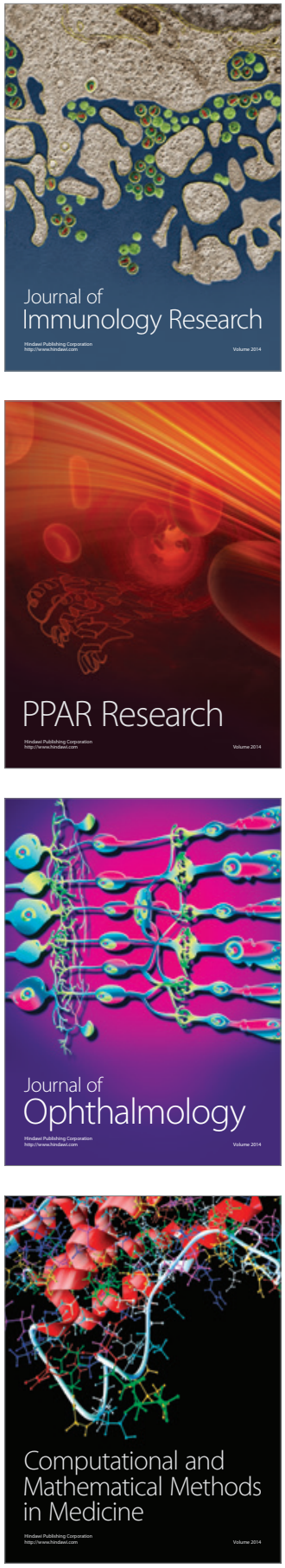

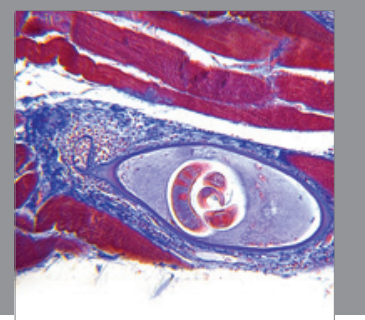

Gastroenterology

Research and Practice
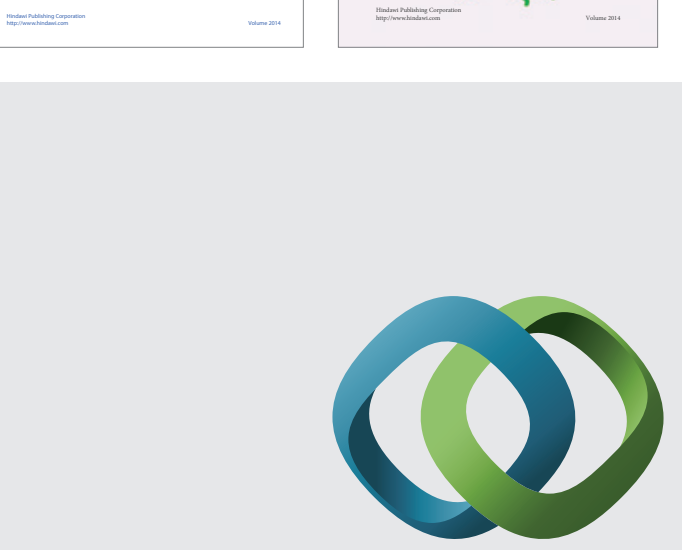

\section{Hindawi}

Submit your manuscripts at

http://www.hindawi.com
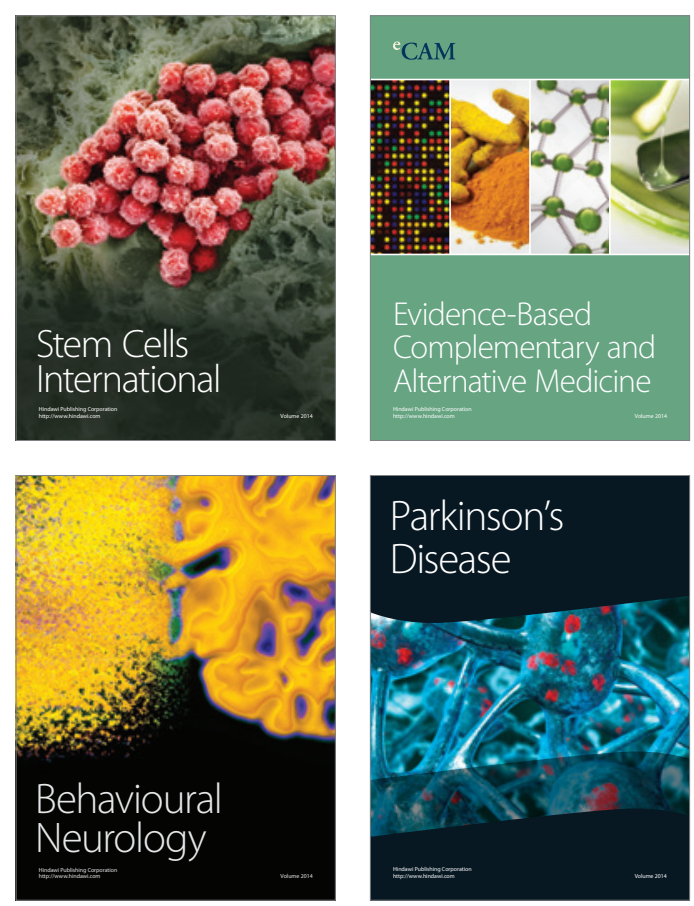

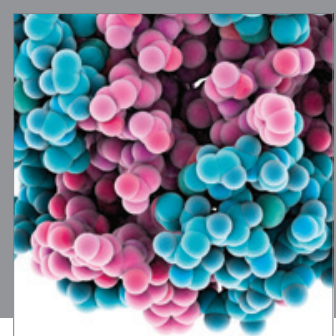

Journal of
Diabetes Research

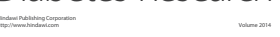

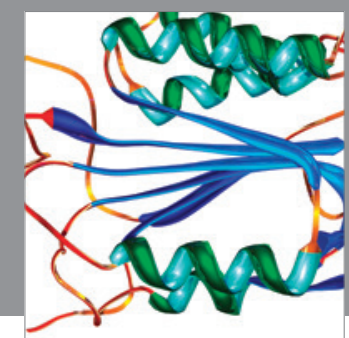

Disease Markers
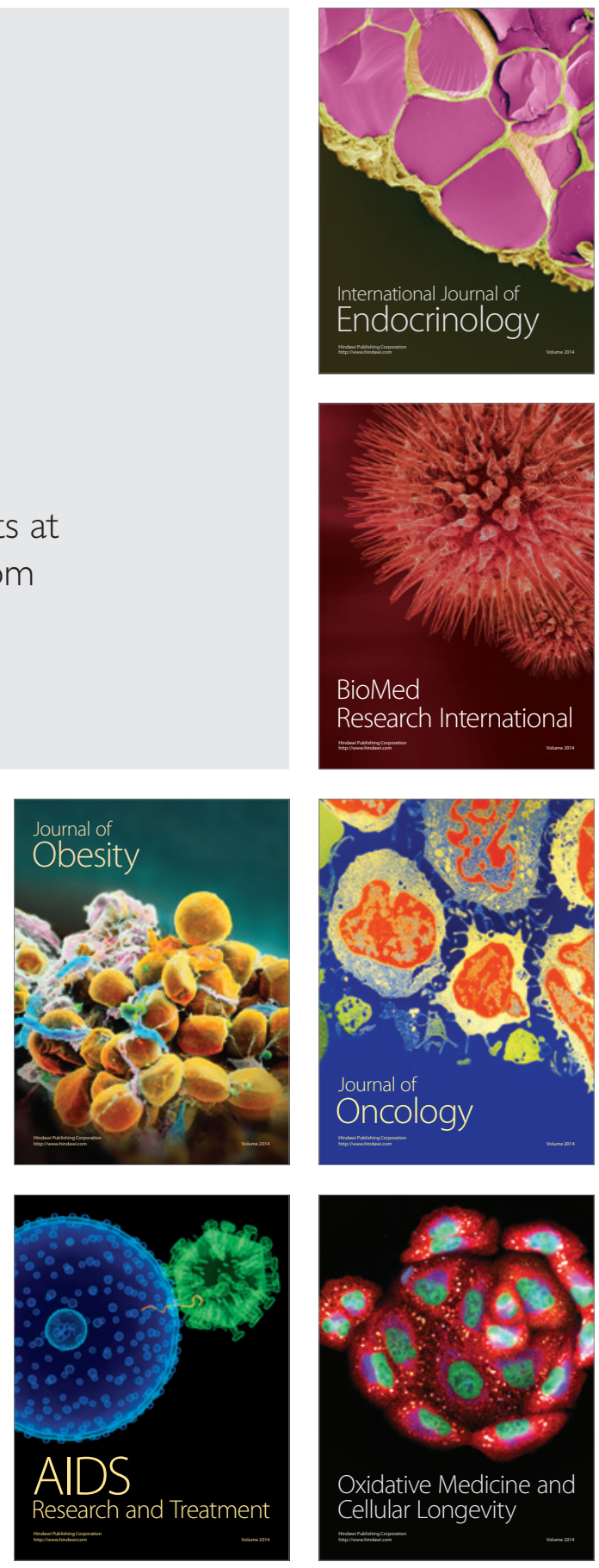